\title{
Viewpoint
}

\section{Disseminating healthcare information: getting the message across}

\author{
S Marriott, C Palmer, P Lelliott
}

\section{Introduction}

It has been shown that there are often significant delays in incorporating clinical recommendations into routine practice. ${ }^{1}$ The biomedical knowledge base is expected to have doubled in size within the next 20 years; however, there is already evidence that even the existing volume of scientific information is unmanageable to those who use it (box 1). ${ }^{2}$ Its sources are diffuse and disorganised. For doctors alone, these sources can include the medical and popular media; recommendations of professional, political, and legal bodies; the output from educational campaigns and programmes; as well as marketing material from commercial sectors allied to health care, in particular the pharmaceutical and medical appliances industries. These are quite apart from internal, day to day information generated within doctors' own organisations. In a review of 13 well designed qualitative or quantitative studies exploring doctors' information needs, it was ascertained that they needed enormous amounts of information most of which was usually inaccessible. ${ }^{3}$

What are the implications of these findings in a public health service committed to providing efficient and effective care ${ }^{4}$ Evidence-based practice calls for the rapid incorporation of best available evidence into routine practice. An important issue for those concerned with developing the policies on which clinical practice is based, including researchers, policy makers, and professional bodies, is how to connect the rapidly expanding knowledge base of health care to the needs of the professionals who deliver it. Dissemination is an essential component of the quality improvement cycle, ensuring the best available evidence is incorporated into routine practice with the smallest possible delay.

\section{S Marriott, consultant}

Centre, UK psychiatrist

College Research Unit, London, UK C Palmer, clinical effectiveness programme manager

P Lelliott, director

Correspondence to: Dr S Marriott, Department of Psychiatry, Paterson Centre, North West London Trust, 20 South Wharf Road, London W2 1PD, UK.
- Established delays in incorporating evidence into routine practice

- Rapidly expanding biomedical knowledge base

- Diffuse and disorganised information sources

- Information overload

Box 1 Factors indicating the need for more effective dissemination
In 1993, the Royal College of Psychiatrists' research unit undertook a literature review of the theory and practice of dissemination as part of a diverse programme of quality improvement initiatives. In this article we report the findings of this review. We begin by describing a framework that maps each group of important theories for dissemination, and then examine the findings of a few well designed evaluations of dissemination strategies. We conclude by summarising the essential stages in the design of a strategy that is likely to have the greatest possible impact. The article is therefore of particular interest to those supporting or providing effective clinical practice locally, including clinicians, senior managers, and policy makers.

\section{What is dissemination?}

Making an audience aware of new and relevant information is termed "dissemination" which literally means "to scatter, or sow". ${ }^{5}$ However, when the term is applied to achieving an effective flow of information between a source and audience, it is important that the process is not haphazard, like the scattering of seeds. The event should be more carefully planned, targeted towards, and tailored to the needs of its intended audience (box 2). ${ }^{6}$ Dissemination strategies are designed to alert an audience and make them aware of new knowledge. They are usually distinguished from implementation strategies, which aim to achieve change in the audience's actions or behaviour. In practice, there is considerable overlap between dissemination and implementation and they exist on a continuum because adequate awareness and understanding is usually an essential precondition for changing behaviour.

\section{How dissemination achieves awareness}

Theories which help to explain or describe the dissemination of information can be grouped into several categories, which describe important characteristics of (a) the environment in which information movement or transfer occurs, (b) the information's audience, and (c) those of the information, or message, itself (box $3)$.

\section{ENVIRONMENT}

\section{Social influence}

Three theories are important in understanding the relation between information flowing to- 
- Who needs to know (audience(s))?

- What do they need to know (content)?

- Who do they need to hear it from (source)?

- How can they best be reached (vehicle)?

- Who or what might influence their attitude to the message they receive (context/ environment)?

Box 2 Questions that drive the design of dissemination strategy

wards an audience and the environment in which this movement occurs. It has long been recognised that an individual's attitudes are influenced by those around them. In 1898, Triplett conducted one of the first social psychology experiments when he examined the average time taken by a group of children to complete 150 winds of a fishing reel, first alone and then in pairs. $^{7}$ Performance was clearly superior in the paired conditions, and he concluded that merely being in the presence of others is enough to change our behaviour. Social influence theory holds that judgments and beliefs of our peers play a major part in an individual's evaluation of new information and their own judgments about it.

Flow hypothesis

The work of Lazarsfeld et al provided evidence that the flow of information towards its audience is achieved in stages. ${ }^{8}$ Lazarsfeld developed the "two step flow hypothesis" when he examined the voting behaviour of American citizens. He found the majority of voters were influenced more by their peers and colleagues than by media reporting directly, and characterised these "opinion leaders" as people who were technically competent, accessible, and acceptable in the eyes of their peer group. This mediating function was examined further by Menzel and Katz, ${ }^{9}$ who questioned how doctors came to adopt new drugs. They suggested that a three or four step cascade more accurately described this flow between the media and local agents, noting that opinion leaders themselves looked to colleagues, usually of an even higher status than themselves, in formulating their views.

\section{Information transfer}

The flow, or transfer, of information from source to audience has been succinctly described by Lomas, ${ }^{6}$ who described and contrasted two models, which he termed "diffusion" and "dissemination". In the diffusion model, information flows away from it origin, as light is emitted from a bulb. The process is passive and untargeted. The effective transfer of information diffusing in this way depends heavily on its audience's interest, or motivation, and their efforts to seek it out. Textbooks, clinical journals, and web sites rely on this type of information flow. In contrast, dissemination, like the beam of a torch, carries with it the implication of a target or goal and is more proactive and premeditated. Examples include undergraduate and postgraduate education programmes; campaigns of oral presentations, such as those used by the pharmaceutical industry in promoting their products; fax cascades; or targeted mailings.

\section{AUDIENCE}

Multiprofessional health care

To target information accurately a clear idea of the intended audience is needed (box 3). Who needs to know? A great deal of health care today is focused on the activity of groups of professionals working together in teams in a coordinated way, rather than on individuals or single professional groups. The Royal College of Psychiatrists' clinical guideline, The Management of Imminent Violence, ${ }^{10}$ includes a wide range of recommendations for improving team working, supporting practices to ensure safety throughout an organisation not just in the clinical environment, and a stable managerial framework within which clinical care can be provided, as well as recommendations for effective clinical practice. The brief version of the guideline was not only disseminated to each college member but there were also bulk mailings to the representative professional organisations of allied health professions, as well as to the chief executives of all trusts providing specialist mental health services in the UK.

\section{Existing attitudes}

How much truth is there in the saying "human beings are creatures of habit?" How someone behaves in response to new information will depend to an extent on the nature of their existing beliefs and attitudes, their habitual behaviour, and the extent of change called for in either. Attitudes can be defined as likes and dislikes, ${ }^{11}$ and are usually understood as a blend of an individual's knowledge and beliefs about the world and their values. Until the mid-20th century the term attitude was usually used to describe a person's characteristic posture, and was seen as largely innate and ingrained and difficult to change. ${ }^{12}$ The propensity to adopt new ideas can be understood as an individual characteristic, and one that can be expected to show a normal distribution in

Environment

- An active or passive process?

- Opinion leader cascade or local agents available or needed?

\section{Audience}

- Individuals, groups, teams, or organisations to involve?

- Their existing attitudes and beliefs?

- Their readiness to change?

Message

- Source: (a) credibility and (b) proximity?

- Content: (a) brevity and (b) consistency with exiting beliefs?

- Vehicle or channel: (a) appropriateness and accessibility to the intended audience(s) and (b) opportunities for systematic instruction?

Box 3 Separate components that can be considered in the design of a dissemination strategy 
any population. Professionals are no exception. In between "innovators" (those individuals who have the greatest contact with expert sources, are the most open to novel ideas, and are the most inclined to adopt them) and "laggards" (who exercise the greatest resistance and suspicion to such innovation), are a majority who adopt change with caution. ${ }^{13}$ The theory of "preparedness to change" ${ }^{14}$ refers to change in attitude and behaviour. It outlines stages of change with reference to "precontemplators", or those who are not yet convinced that current ideas are acceptable; "contemplators" who have begun to consider and question innovative ideas; "actioners" who are changing their own views, and consequently their behaviours; and "maintainers" who are consolidating these changes and sustaining them. It has been suggested therefore that the rate of adoption can be accelerated if progressively more intensive strategies of persuasion, from information provision to intensive education, are provided to those less inclined to adapt. ${ }^{15}$

MESSAGE

Three characteristics are important: (a) the source from which the message emanates, (b) the content of the message, and (c) the vehicle by which the message is conveyed (box 3 ).

\section{Source}

Important features of the information source include its perceived credibility with, and proximity to, the target audience.

Credibility - The perceived authority, and honesty, of the message seems to exert influence on the extent to which it is believed, and this is related to its source. In 1951, for example, a group of American subjects were asked about the truth of two statements about antihistamines, one originating from the New England fournal of Medicine and the other from a popular newspaper. Although there was no difference in how the accounts were remembered, the audience were more likely to be convinced by the account given in the medical journal. More recently Tunis et al examined clinicians' knowledge of, and attitude towards, two nationally disseminated clinical guidelines using a stratified sample. ${ }^{16}$ Although both guidelines had been widely disseminated they found that some participants had heard of neither. The first guideline, endorsed by a national professional organisation, scored highly among participants for credibility. Despite this, many reported that they were not applying the recommendations routinely in their practice. The second guideline, on the same topic but endorsed by a health insurance organisation, was accorded less credibility and was perceived as still less likely to be used than the first. The findings are surprising when it is revealed that the technical content of the two documents was virtually identical. The simple provision of information is not sufficient to ensure awareness. Its quality does not guarantee that it will be believed. Even if it is believed, the audience's behaviour may continue unchanged.
Proximity-Grimshaw and Russell ${ }^{17}$ used 59 well designed, published evaluations of clinical guidelines to evaluate the extent of improvements in clinical process or health outcome. ${ }^{17}$ They suggested that developing and disseminating guidelines was a central rather than local task, arguing that their local adaptation from general statements into locally tailored protocols improved their acceptability to those who needed to use them, and their relevance to the environment they worked in.

Content

The message's content may also influence the extent to which an audience assimilates it.

Clarity and brevity - The relentless advance of technical knowledge is nowhere more evident than in the field of health care, and the risks of information overload are widely acknowledged. A stratified random sample of 2600 doctors were asked their views about the most appropriate presentation of clinical guideline recommendations using a simple ordinal scale. Findings suggested that clinicians valued brevity and clarity of recommended actions, while also seeking a summary of the evidence supporting each recommendation. ${ }^{18}$ There is some evidence that an audience may also be influenced positively by its perception of the source's objectivity, or disinterest and negatively if it entertains suspicions of self interest. ${ }^{19}$ Information sources which provide relevant, valid material that can be accessed quickly with minimal effort are the least likely to be ignored. $^{2}$ Awareness may also be increased through the visual impact of the messagethrough the use of information summaries in the form of charts, tables, illustrations, and logos.

Consistency with existing beliefs and attitudes - It is generally agreed that whatever the message it is difficult to change people's attitudes. The theory of cognitive consistency is regarded as the most influential explanation of attitude change..$^{19}$ It states that people sort through and modify many cognitive items to achieve agreement. Whenever an individual simultaneously holds two ideas, or cognitions, which are inconsistent with each other, they experience a measure of psychological dissonance or tension. When this happens, attitude change is one way of reducing this tension. This theory predicts that information which is compatible with existing beliefs is the most likely to be accepted, ${ }^{20} 21$ and that which emphasises the undesirable qualities of items which have already been accepted may be selectively avoided or ignored.

\section{Vehicle or channel}

Appropriateness to target audience-This describes the channel by which the information reaches its source. To reach the widest possible audience a mass communication network is appropriate. This includes national and regional television and radio, the popular media, and the internet. When the intended audience is more defined, however, other channels may 
prove more appropriate. For instance, for a medical audience these might include the medical media or national conferences and targeted mailing of relevant information by post. For a local audience, email, internal post, and small group workshops are feasible and might prove most useful.

Opportunities for systematic instruction - Even when new information has been acknowledged, learning is essential if it is to be understood and retained. Learning is regarded as an innate process, which implies a relatively permanent change in a person's knowledge and potential (but not actual) behaviour. It is intricately related to memory, so that learning depends on memory for its permanency, and memory depends on learning for its content. The three major theories of learning are cognitive, conditioned, and observational (or social) learning. Cognitive learning is achieved largely through methods of systematic instruction and, in the professional domain, through education. Educational meetings, workshops, and clinical apprenticeships are familiar interventions that place emphasis on communicating information through systematic instruction.

\section{Effective components of dissemination strategies}

Several well designed, systematic reviews have attempted to examine the effectiveness of different types of dissemination. Achieving validity and reliability in the measurement of knowledge, awareness, and attitudes is difficult, ${ }^{22}$ and reviews have usually used change in the target audience's behaviour, or used performance as a more robust outcome measurement, or where strategies support awareness of clinically effective practices, have measured improvement in health outcomes. A recent review has examined the effectiveness of mass media campaigns in modifying the use of health services. ${ }^{23}$ Although the reviewers were confronted with methodological flaws in the design of relevant trials, they found consistent support for the use of the media in promoting uptake of research findings. The simple provision of information was examined in a systematic review of 11 studies of the dissemination of printed educational materials comparing this with no active intervention, as well as an enhanced intervention that combined it with an educational or marketing strategy. The effects were small, but increased when additional strategies were added. Of these, individual educational outreach sessions and the use of local opinion leaders as agents of dissemination appeared promising. ${ }^{24}$ The benefits of using local opinion leaders as agents of dissemination were not unequivocally shown when examined in a later review. ${ }^{25}$ In contrast, educational outreach visits have been the topic of a further review and the findings indicate it is a promising approach. However, outreach is a complex intervention comprising at least a face to face visit from an educator to a practitioner, but usually also includes at least one additional learning method, including conferences and written materials. In a system- atic review the relative effectiveness of some of these accompanying learning methods was examined, using trials in which physicians were randomly allocated to strategies for continuing medical education. ${ }^{26}$ When compared with more intensive educational interventions, those that relied most on simply raising awareness, such as conferences, and without any accompanying change enabling strategy appeared to have the least impact on practitioner behaviour or health outcome. Styles of medical education were separated into four categories and compared according to the intensity of instruction ${ }^{27}$ :

- Low intensity interventions such as conferences or printed materials

- Moderate intensity interventions such as making available clinical guidelines accompanied by tailored teaching methods

- High intensity interventions such as individual practitioner performance feedback

- Combined interventions of different intensities.

The lowest intensity interventions, attempting only to raise awareness, had the least impact on professional knowledge and behaviour. Each of these reviews suggest that educational interventions strengthen the effect of clinical educational material, and that the more intensively information is provided through these approaches the greater its effect on its recipients. Even where dissemination tactics are carefully planned and material reaches its audience, the impact of the information may remain low. Some evidence exists to suggest this can be influenced by the channel chosen to disseminate the information and the intensity with which it is delivered. The clinical and cost effectiveness of these approaches remains unclear.

\section{Conclusions}

We have presented the case for dissemination as an essential, if often overlooked, component of quality improvement. It provides an essential link between research and policy describing best practice and the delivery of clinically effective care.

Health care today is usually provided by teams of individuals working together and supported by large and complex organisations. Communicating information to all those that might need it, and in a way that is relevant to their task, is a considerable undertaking in itself. The simple provision of information is unlikely to be sufficient, however. We have described a framework around which a dissemination strategy can be designed. The process is best understood as one which is accomplished in stages, and any strategy is likely to have more than one component. It should include recognition of the characteristics of the individuals, or groups of individuals, who need to be made aware; the channels through which they can be reached; the message they need to receive; and influential factors that may be operating in their professional environment. In many cases this may well mean multiple audiences being approached through various pathways, each 
receiving a message tailored to their own task and information needs. Just as importantly, measures should be taken to avoid overloading them with information they cannot, or will not, use.

1 Antman EM, Lau J, Kupelnick B. A comparison of results of meta-analyses of randomised controlled trials and recommendations of clinical experts. Treatment for myocardial infarction. $7 A M A$ 1992;268:240-8.

2 Williamson JW, German PS, Weiss R, et al. Health science information management and continuing education of phyinformation management and continuing education of physicians. A survey of US primary care practitioners
opinion leaders. Ann Intern Med 1989;10:151-60.

3 Spinion leaders. Ann Intern Med 1989;10:151-60. do doctors need? BMF 1996;313:1062-8.

do doctors need? $B M f$ 1996;313:1062-8. Depar 1998.

5 Anonymous. The concise Oxford dictionary. Seventh edition. Oxford: Oxford University Press, 1997.

6 Lomas J. Diffusion, dissemination and implementation. Annals of the New York Academy of Sciences 1993;703:22657.

7 Triplett N. The dynamogenic factors in pacemaking and competition. Am f Psychol 1898;9:507-33.

8 Lazarsfeld PF, Berelson B, Gaudet H. The people's choice: how the voter makes up his mind in a presidential campaign. New York: New York Columbia University, 1948.

9 Menzel H, Katz E. Social relations and innovation in the medical profession: the epidemiology of a new drug. Public medical profession: the epidemio

10 Wing J, Marriott S, Palmer C, et al. The management of imminent violence: clinical practice guidelines to support mental
health services. London: Royal College of Psychiatrists, 1998.

11 Bem DJ. Self perception: on alternative interpretation of 1 Bem DJ. Self perception: on alternative interpretation of cognitiv

12 Miller GA. Psychology: the science of mental life. Hammondsworth: Penguin, 1966.

13 Becker MH. Sociometric location and innovativeness: reformulation and extension of the diffusion model. Am Socio Rev 1970;35:267-82.
14 Prochaska JO, DiClimente CC. In: Miller WR, Heather N, editors. Treating addictive behaviours: processes of change. New York: Plenum Press, 1986

15 Zaltman G, Duncan R. Strategies for planned change. New York: Wiley, 1997.

16 Tunis SR, Hayward RSA, Wilson MC, et al. Internists' attitudes about clinical practice guidelines. Ann Intern Med 1994;120:956-63.

17 Grimshaw JM, Russell IT. Effect of clinical guidelines on medical practice: a systematic review of rigorous evaluations. Lancet 1993;342:1317-22.

18 Hayward RSA, Wilson MC, Tunis SR, et al. More informative abstract of articles describing clinical practice guidelines. Ann Intern Med 1993;118:731-7.

19 Festinger LA. Theory of cognitive dissidence towards a comprehensive model of change. New York: Harper and Row, 1957.

20 Rogers E. Diffusion of innovations. New York: The Free Press, 1983.

21 Stocking B. Promoting change in clinical practice. Quality in Health Care 1992;1:56-60.

22 Gross R. Psychology: the science of mind and behaviour. 3rd edition. London: Houghton and Stodder, 1987

23 Grilli R, Freemantle N, Minozzi S, et al. Mass media interventions: effects on health service utilisation. The Cochrane Database of Systematic Reviews. Cochrane Library: issue 2, 1999 .

24 Freemantle N, Harvey EL, Wolf F, et al. Collaboration on effective professional practice module. The Cochrane Database of Systematic Reviews. Cochrane Library: issue 2, 1999.

25 Thomson O'Brien MA, Oxman AD, Haynes RB, et al. Local opinion leaders: effects on professional practice and health care outcomes. The Cochrane Database of Systematic Reviews. Cochrane Library: issue 2, 1999.

26 Davis DA, Thompson MA, Oxman AD, et al. Evidence for the effectiveness of continuing medical education: a review of fifty randomised controlled trials. $\mathcal{F} A M A$ 1992;268:1111-

27 Davis D, Thompson MA, Oxman AD, et al. Changing physician performance: a systematic review of the effect of continuing medical education strategies. $\mathcal{F} A M A$ 1995;274:700- 